\title{
Prednisolone encapsulated PLGA nanoparticles: Characterization, cytotoxicity, and anti-inflammatory activity on C6 glial cells
}

\author{
Sriprasad Acharya ${ }^{1}$, Bharath Raja Guru ${ }^{2 *}$ \\ ${ }^{1}$ Department of Chemical Engineering, Manipal Institute of Technology, Manipal Academy of Higher Education, Manipal 576104, India. \\ ${ }^{2}$ Department of Biotechnology, Manipal Institute of Technology, Manipal Academy of Higher Education, Manipal 576104, India.
}

\section{ARTICLE INFO \\ Received on: 03/10/2019 \\ Accepted on: 20/01/2020 \\ Available online: 04/04/2020}

Key words:

Prednisolone nanoparticles, anti-inflammatory, cytotoxicity, factorial design.

\begin{abstract}
Prednisolone, a popular glucocorticoid (GC) known for its ability to inhibit cytokine release, is also employed extensively in cancer therapy. GCs have been used to treat brain tumors to reduce tumor-associated edema. They are known to exhibit different effects on different cell lines and in some cases are known to be neurotoxic. In this study, we have investigated and compared the cytotoxic and anti-inflammatory effects of prednisolone and prednisolone encapsulated Poly Lactic-co-Glycolic acid (PLGA) nanoparticles (NPs) on C6 cells that are cancerous but are known for their similarity to astrocyte cells. Design expert software was used to analyze the effect of different variables for NP formulation. By varying different parameters, NPs were synthesized and characterized using particle size analyzer and zeta potential. The surface morphology of the NPs was analyzed using scanning electron microscopy. Lipopolysaccharide activated C6 glial cells witnessed significantly lower cell proliferation in the presence of the drug during the 48 hours of incubation and the prednisolone encapsulated NPs were able to attenuate pro-inflammatory cytokines like Tumor necrosis factor alpha (TNF- $\alpha$ ) and nitric oxide substantially even after the 72 hours of incubation when compared with the free drug. The results suggested that prednisolone was more effective as an anti-inflammatory drug in the PLGA nanoformulation.
\end{abstract}

\section{INTRODUCTION}

Synthetic glucocorticoids (GCs) like prednisolone are extensively employed to treat many autoimmune and inflammatory-related diseases (Baschant and Tuckermann, 2010; Clark and Belvisi, 2012). They also play a central role in cancer therapy (Lin and Wang, 2016). The antineoplastic effects of GCs like dexamethasone and prednisolone have enhanced their effects in treating patients with chronic leukemia, multiple myeloma, and Central nervous system (CNS) lymphoma (Inaba and Pui, 2010; Todd et al., 1986). They assist in appetite enhancement, controlling nausea, vomiting, and reducing tumor-associated edema. They are also known to be cytotoxic toward lymphoblastic leukemia cells (Bindreither et al., 2014), whereas dexamethasone has shown to

*Corresponding Author

Bharath Raja Guru, Department of Biotechnology, Manipal Institute of Technology, Manipal Academy of Higher Education, Manipal 576104, India. E-mail: bharath.guru@manipal.edu augment serum deficient necrotic cell death in $\mathrm{C} 6$ cell lines (Morita et al., 1999). GCs act mainly through the GC receptor's present in the cytoplasm undergoing complex and distinct molecular mechanisms to achieve the anti-inflammatory and cytotoxic effects (Baschant and Tuckermann, 2010). They are also known to interact with transcription factors like Nuclear Factor (NF)- $\mathrm{kB}$, whose inhibition results in the attenuation of many cytokines. Like any other steroid, prednisolone when used in large doses leads to severe mood swings, loss of memory, depression, and insomnia (Christoper et al., 2014; Makadia and Siegel, 2011). Their use leads to the suppression of the immune systems, which in turn increases the chances of infections. Thus a sustained delivery of the drug, encapsulated in biodegradable Poly Lactic-co-Glycolic Acid (PLGA) nanoparticles (NP) may help to achieve an effective treatment with safer quantities of drug employed, leading to minimal side effects.

Biodegradable polymers like PLGA are extremely popular due to their biocompatibility (Mundargi et al., 2008) and are among the classic carrier polymers for drug delivery applications (Danhier et al., 2012). They exhibit minimal toxicity (Boekhorst te et al., 2012) and the byproducts formed after degradation is easily excreted 
from our body through the Krebs cycle (Locatelli and Franchini, 2012; Shive and Anderson, 1997). Its inherent structure allows it to act as an excellent reservoir to encapsulate many known drugs and also degrade in aqueous solutions (Ford Versypt et al., 2013). The amphiphilic nature of PLGA protects it from the hydrophilic environment. Furthermore, studies (ElShaer et al., 2016; Giovagnoli et al., 2008; Khaled et al., 2010) have shown that there is little to no interaction between the polymer and the prednisolone drug. It is also a US the Food and Drug Administration (FDA) approved polymer (Brown and Chandler, 2001) known to release encapsulated drugs in a sustained manner (Ciriaco et al., 2013).

In this study, we formulated, characterized, and analyzed the prednisolone loaded PLGA NPs using factorial design. In vitro release of the drug from the NPs in phosphate buffer (of $\mathrm{pH} 4.5$ and 7.4) was carried out and the cytotoxicity and efficacy of these NPs were evaluated in comparison to the free drug by measuring the release of pro-inflammatory cytokines like Tumor necrosis factor alpha (TNF- $\alpha$ ) and nitric oxide (NO).

\section{MATERIALS AND METHODS}

\section{Materials}

PLGA (50:50) (MW: 100,000-120,000) was procured through Durect Corp. AL, USA. Polyvinyl alcohol (PVA) (MW: 13,000), Acetonitrile, Coumarin 6, lipopolysaccharide (LPS), 4',6-diamidino-2-phenylindole (DAPI), and prednisolone were purchased from SIAL (MERK, India). Tri-fluroacetic acid (TFA) and dimethyl sulfoxide (DMSO) were purchased from Loba Chemie, Mumbai. Ham's F-12K medium, fetal bovine serum (FBS), trypsin, penicillin-streptomycin, 3-(4,5-dimethylthiazol-2-yl)-2,5diphenyltetrazolium bromide (MTT), and nitrate/nitrite assay kit were purchased from HiMedia (Mumbai). The TNF- $\alpha$ Rat Enzymelinked immunosorbent assay (ELISA) kit was procured from Krishgen BioSystems (Mumbai). The rest of the chemicals and the reagents were of analytical grade and commercially available.

\section{Preparation of prednisolone encapsulated nanoparticles}

Prednisolone $(8 \mathrm{mg} / 20 \mathrm{mg})$ and PLGA $(40 \mathrm{mg})$ were allowed to dissolve in about $2 \mathrm{ml}$ of chloroform for $4-5$ hours. This organic phase was added into a $15 \mathrm{ml}$ solution of $(1 \%-3 \%$ $\mathrm{w} / \mathrm{v}$ ) aqueous PVA. The emulsion formation was facilitated by employing a probe sonicator for 4 to 8 minutes over an ice bath. The emulsion was stirred overnight at room temperature followed by 2 hours under vacuum to remove the traces of chloroform. To remove the excess PVA, the NPs were centrifuged (30 minutes, $\left.4^{\circ} \mathrm{C}, 15,000 \mathrm{rpm}\right)$, sonicated (20 seconds), and washed with deionized water thrice. Dispersed NPs in pure water were freezedried prior to storage at $-20^{\circ} \mathrm{C}$.

\section{Nanoparticle characterization}

The NPs (1 mg) were suspended in millipore water $(5 \mathrm{ml})$ and sonicated in a bath sonicator (30 seconds) before analysis. The average particle size and zeta potential of the developed NPs were determined using Malvern Zetasizer nano ZS (Malvern Instruments, Malvern, Worcestershire, UK).

\section{HPLC method}

Analysis of prednisolone was done using reverse phase HPLC, equipped with auto sampler and UV detector (SPD-20A), model no. LC-20AD by SHIMADZU. The separation was carried out on a ZORBAX Eclipse plus-C18 column, $3.5 \mu \mathrm{m}, 100 \AA$ at $254 \mathrm{~nm}$. The mobile phase was made up of water $(60 \%)$ and acetonitrile $(40 \%)$ containing $0.1 \%$ TFA and was pumped at 0.5 $\mathrm{ml} / \mathrm{min}$.

\section{Drug loading efficiency of nanoparticles}

The NPs containing the drug $(1 \mathrm{mg})$ were dissolved in $1 \mathrm{ml}$ methanol (triplicate) and kept on a rocker shaker for 48 hours. After centrifuging at 10,000 rpm for 20 minutes, the supernatants were kept overnight for methanol evaporation. These samples were then dissolved in $1 \mathrm{ml}$ acetonitrile and analyzed using Reversed Phase - High Performance Liquid Chromatography (RP-HPLC).

\section{In vitro drug release study}

A basic in vitro drug release profile was studied in a buffer solution, so as to simulate the human body condition for the drug encapsulated PLGA NPs. Two different buffer solutions of pH 7.4 (physiological) and $\mathrm{pH} 4.5$ (lysosome) were employed to study the release profile. The lyophilized NPs ( $3 \mathrm{mg}$ ) in triplicates were weighed and dispersed in buffer solutions. The tubes were incubated at $37^{\circ} \mathrm{C}$ on a shaker and at predetermined time intervals, centrifuged (10,000 rpm, 20 minutes) and the supernatant solutions collected were analyzed using RP-HPLC.

\section{Stability study of prednisolone}

Prednisolone $(1 \mathrm{mg})$ was dissolved in $1 \mathrm{ml}$ of $\mathrm{pH} 7.4$ and $\mathrm{pH} 4.5$ buffer. After achieving maximum dissolution, the supernatant was separated by centrifugation. These samples were incubated at $37^{\circ} \mathrm{C}$ and the supernatant was subjected to RP-HPLC for a period of 15 days.

\section{Cell culture}

C6 glial cells were obtained from National Centre for Cell Science (NCCS), Pune, India. The cells were grown in $25 \mathrm{~mm}^{2}$ flasks using Ham's F-12K media with $10 \% \mathrm{FBS}$ and $1 \%$ penicillinstreptomycin in an incubator at $37^{\circ} \mathrm{C}$ and $5 \% \mathrm{CO}_{2}$. The media was changed every $2-3$ days and the cells were split when $70 \%-80 \%$ confluent using $0.25 \%$ trypsin-Ethylenediaminetetraacetic acid (EDTA)

\section{Uptake assay with fluorescent particles}

To visualize the particle uptake, C6 cells were seeded and allowed to attach for 24 hours. The media was removed and washed with Phosphate buffered saline (PBS) (3X). These cells were then incubated with coumarin-6 loaded PLGA NPs $(1 \mu \mathrm{g} /$ $\mathrm{ml}$ ) for 30 minutes followed by wash $(3 \mathrm{X})$ and DAPI $(500 \mathrm{ng} /$ $\mathrm{ml})$ staining for 10 minutes. The cells were then observed under Olympus IX73P1F fluorescence microscope.

\section{Cell treatment}

C6 glial cells were seeded in 24 well plates with a cell density of $10^{5} / \mathrm{ml}$. A working volume of $0.5 \mathrm{ml} /$ well was maintained throughout the experiment. After 24 hours of incubation, the media was aspirated from all the wells and washed with PBS. This was followed by the addition of $0.5 \mathrm{ml}$ of serum free media (SFM) containing $100 \mathrm{ng} / \mathrm{ml}$ of LPS to induce cytokine production. The negative control wells only received SFM. After incubating for 
6 hours, the media was aspirated and replaced with SFM + LPS media containing fixed concentrations $(5,10$, and $15 \mu \mathrm{g} / \mathrm{ml})$ of the free drug (prednisolone) and PLGA NPs (S6) containing the drug. The control wells received no drug treatment. After 12 hours of further incubation, the media was aspirated and gently washed with PBS. The wells were refilled with SFM + LPS media and incubated further for a period of 24,48 , and 72 hours. The culture media was collected at these time intervals, centrifuged at $1,400 \mathrm{rpm}$ for 5 minutes and the supernatant stored at $-80^{\circ} \mathrm{C}$ for further analysis.

\section{Cell cytotoxicity assay}

Cell viability study was conducted after the collection of media from the 24 well plates. Briefly, $200 \mu \mathrm{l}$ of MTT was added to each well and incubated for a period of 5 hours. The MTT solution was replaced with $200 \mu \mathrm{l}$ of DMSO to dissolve the formazan crystals and the absorbance was recorded using a Thermo Scientific varioskan lux microplate reader at $570 \mathrm{~nm}$. The cell viability was assessed in terms of the percentage of positive control.

\section{NO release assay}

Nitrite production was measured using EZAssay NO estimation kit according to the manufacturer's instructions. In brief, $100 \mu \mathrm{l}$ of supernatant was mixed with $50 \mu \mathrm{l}$ Griess reagent I and then with $50 \mu \mathrm{l}$ of Griess reagent II. The absorbance was measured at 580 and $630 \mathrm{~nm}$ and the concentration was determined from the calibration curve obtained from the nitrite standards.

\section{TNF-alpha ELISA}

TNF- $\alpha$ cytokine production by $\mathrm{C} 6$ glial cells was analyzed using the ELISA kit according to the manufacturer's instructions. Briefly, $100 \mu$ of the samples were added to designated wells and incubated for 2 hours at room temperature (RT). The solutions were thoroughly aspirated and washed (4X) with a wash buffer. Later $100 \mu \mathrm{l}$ of Rat TNF- $\alpha$ Biotin conjugate solution was added to all wells except the blanks and further incubated for 1 hour
(RT). The solutions were again thoroughly aspirated and washed (4X) with the wash buffer. Next, $100 \mu \mathrm{l}$ of Strep.-Horseradish peroxidase (HRP) was added to all wells (except blanks) and the plate was incubated for 30 minutes (RT) followed by wash (4X). Finally, $100 \mu \mathrm{l}$ of stabilized chromogen was added to all wells and incubated for 30 minutes in the dark followed by the addition of an equal quantity of stop solution turning the blue solution to yellow. The absorbance was read immediately at $450 \mathrm{~nm}$ and the unknown concentrations were determined from the standard fit curve.

\section{Statistical analysis}

In this study, we chose three independent factors with two levels in a $2^{3}$ factorial design. A relationship between the independent factors, i.e., drug to polymer ratio (A), \%PVA (B), sonication time (C) and dependent factors, i.e., particle size $\left(\mathrm{D}_{99}\right)$, zeta potential, and drug loading was analyzed using Design Expert software. All other data are presented as mean \pm standard deviation (SD) and analyzed using $t$-test or analysis of variance (ANOVA) with $p$-value less than 0.05 considered as statistically significant.

\section{RESULTS AND DISCUSSION}

The characterized data obtained using Design Expert software are summarized in Table 1. The responses were measured for their dependency on the variables and interactive equations were obtained. The independent variables showed a significant effect on the dependent variables $(p<0.05)$ as seen in the summary of data (Table 2) obtained from the regression analysis. The NPs were in the size range of 172-796.1 $\mathrm{nm}$.

$$
\begin{aligned}
\text { Particle size }= & 406.85-28.43 * \mathrm{~A}+105.38 * \mathrm{~B}-138.35 * \mathrm{C} \\
& -73.4 * \mathrm{AB} \\
\mathrm{Z} . \text { Potential }= & -14.9-0.050 * \mathrm{~A}-1.18 * \mathrm{~B}-1.7 * \mathrm{C}+ \\
& 0.8750 * \mathrm{BC} \\
\text { Drug loading }= & 98.95+86.85 * \mathrm{~A}+5.36 * \mathrm{~B}+10.84 * \mathrm{C}+ \\
& 10.78 * \mathrm{AC}
\end{aligned}
$$

Table 1. $2^{3}$ factorial design of prednisolone loaded PLGA NP formulations and the response parameters.

\begin{tabular}{ccccccc}
\hline \multicolumn{3}{c}{ Factors/variables } & \multicolumn{3}{c}{ Responses } \\
\hline Sample & $\begin{array}{c}(\mathbf{A}) \mathbf{D} / \mathbf{P} \\
\text { Ratio }\end{array}$ & $\begin{array}{c}(\mathbf{B}) \mathbf{P V A} \\
\mathbf{( \% )}\end{array}$ & $\begin{array}{c}(\mathbf{C}) \text { Sonication. time } \\
(\mathbf{m i n})\end{array}$ & $\begin{array}{c}\mathbf{D}_{\mathbf{9 9}} \\
(\mathbf{n m})\end{array}$ & $\begin{array}{c}\text { Zeta potential } \\
(\mathbf{m V})\end{array}$ & $\begin{array}{c}\text { Drug loading } \\
(\boldsymbol{\mu g} / \mathbf{m g})\end{array}$ \\
\hline S1 & 0.20 & 1.00 & 4.00 & 341 & -10.9 & 4.03204 \\
S2 & 0.50 & 1.00 & 4.00 & 503.9 & -11.4 & 159.111 \\
S3 & 0.20 & 3.00 & 4.00 & 796.1 & -14.9 & 20.0528 \\
S4 & 0.50 & 3.00 & 4.00 & 539.8 & -15.6 & 169.262 \\
S5 & 0.20 & 1.00 & 8.00 & 172 & -15.8 & 15.5849 \\
S6 & 0.50 & 1.00 & 8.00 & 189 & -16.8 & 195.646 \\
S7 & 0.20 & 3.00 & 8.00 & 432 & -17.8 & 8.7334 \\
S8 & 0.50 & 3.00 & 8.00 & 281 & -16 & 219.217 \\
\hline
\end{tabular}

Table 2. Summary of ANOVA for size, zeta potential, and drug loading

\begin{tabular}{lccccccc}
\hline & Sum of Squares & $\boldsymbol{F}$-value & $\boldsymbol{p}$ value & Mean & SD & CV\% & $\boldsymbol{R}^{2}$ \\
\hline Size & $2.915^{*} 10^{5}$ & 20.81 & 0.0159 & 406.85 & 59.19 & 14.55 & 0.9652 \\
Zeta potential & 40.31 & 12.24 & 0.0335 & -14.9 & 0.9074 & 6.09 & 0.9423 \\
Drug loading & 62499.23 & 186.47 & 0.0006 & 98.95 & 9.15 & 9.25 & 0.996 \\
\hline
\end{tabular}


The analysis revealed that the size of the particle was mainly influenced by the sonication time and PVA concentration. Sonicating during the emulsification process introduces energy into the solution, enabling proper dispersion of phases, and thereby leading to the formation of drug-containing carrier NPs of varying sizes (Fig. 1). The size $\left(D_{99}\right)$ varied from 796.1 to $172 \mathrm{~nm}$ (Fig. 2) for a time interval of 4-8 minutes. An increase in the sonication time resulted in smaller drug encapsulated NPs having lower (negative) zeta potential (Jiang et al., 2009). On the other hand, higher PVA concentration increased the size of the NPs. High viscosity of the medium may have inhibited breakdown of droplets during sonication (Feng and Huang, 2001) resulting in larger sized NPs.

For zeta potential, PVA concentration and sonication time showed a significant negative effect. Higher sonication time and PVA concentrations gave stable NPs (Cooper and Harirforoosh, 2014) with the peak zeta reaching a maximum of $-17.8 \mathrm{mV}$.

For drug loading, an increase in the drug to polymer ratio and sonication time leads to an increase in loading. High organic phase viscosity may have helped in reducing the drug movement into the other phase, resulting in a higher drug loading (Panyam et al., 2004; Song et al., 2009). Higher drug ratio may have facilitated in optimal distribution and loading of the drug within the polymer.

\section{RP-HPLC method and stability study of prednisolone}

Prednisolone was quantified by employing the method mentioned earlier. The resultant peaks were sharp (Fig. 3A) with a retention time of approximately 5.8 minutes at $254 \mathrm{~nm}$. The standard concentration plot (Fig. 3B) was obtained $\left(R^{2}=0.9995\right)$ by co-relating the peak areas. Later, the stability study was performed for a period of 15 days (Fig. 4) at $\mathrm{pH} 7.4$ and $\mathrm{pH} 4.5$. Overall, higher degradation was observed at $\mathrm{pH} 7.4$ (45.74\%) whereas at $\mathrm{pH} 4.5$ showed a slightly lower degradation of $23 \%$. The percentage loss of the drug due to degradation at specific time intervals as quantified using RP-HPLC was later employed as a correction factor during the in vitro release study.

\section{In vitro drug release}

Release study (Fig. 5) carried out at $\mathrm{pH} 4.5$ and 7.4 for the carrier NP with drug loading $(195.789 \mu \mathrm{g} / \mathrm{mg})$ showed an initial burst phase, where nearly $65 \%$ of the drug got released within a span of 3 days. This was followed by a phase of sustained release for a period of over 25 days. The study showed that the drug release rates were almost the same at $\mathrm{pH} 4.5$ and $\mathrm{pH} 7.4$ with a slightly faster and larger release seen under the acidic condition. A total of $80.93 \%$ and $92.3 \%$ release was registered after taking into account the stability of the drug for a period of 30 days for $\mathrm{pH} 7.4$ and 4.5, respectively. As prednisolone in the free drug form is known to have a short half-life, the sustained release of the drug from the PLGA NPs could ensure a therapeutic concentration of the drug for days by protecting the drug from the external environment.

\section{Analysis of particle uptake}

The pretreated C6 cells were viewed under a fluorescence microscope to visualize the uptake of the PLGA NPs containing Coumarin-6. The uptake was captured first in the bright field (Fig. 6A) and later under fluorescence (Fig. 6C) with DAPI stained nucleus (Fig. 6B). The images showed that most of the NPs were internalized immediately (Nicolete et al., 2011) with a large concentration of NPs encircling the nucleus.

\section{Cell cytotoxicity assay}

The effect of prednisolone and NPs containing the drug on cell viability was evaluated using MTT assay for a period of 24, 48 , and 72 hours. A lower concentration of LPS (100 ng/ml) was employed to reduce the cytotoxic effect on the cells (Srivastava et al., 2013). Fig. 7 shows the effect of prednisolone and NPs containing the drug on C6 cells when compared to control. In the initial 24 hours period, the cells treated with the free drug showed slightly lower cell viability when compared to NPs having similar concentration. This may be because the drug from NPs is released sustainably in smaller quantities as shown earlier with the in-vitro release profile. The reduction in viability could have been due to cell death (Morita et al., 1999), growth inhibition (Grasso, 1976),

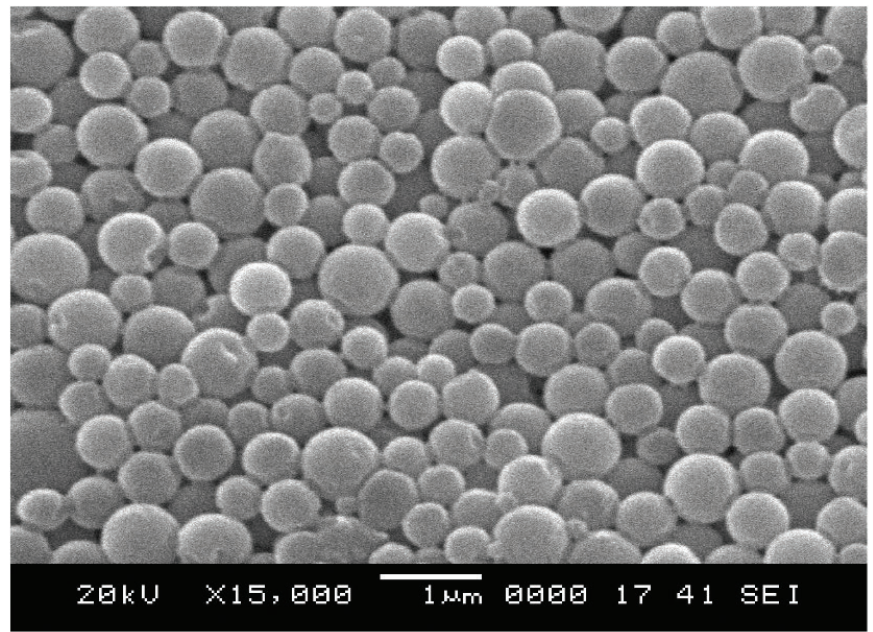

Figure 2. Morphology of the prednisolone loaded PLGA NPs (S3) assessed by scanning electron microscopy.
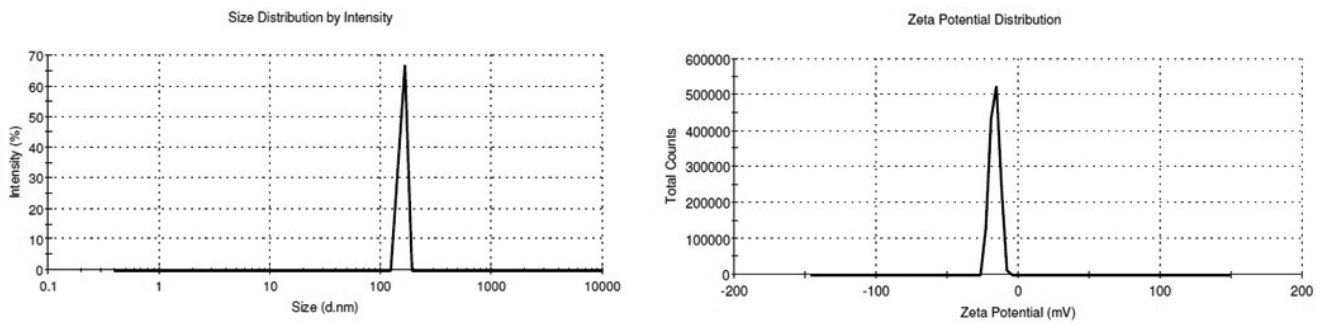

Figure 1. Size distribution and zeta potential of sample (S6). 
or the combination of both. The presence of prednisolone hindered the proliferation of cells during the first two days of treatment in a serum-deprived environment and later a recovery was witnessed due to a reduction in the inhibitory effect, leading to possible cell proliferation. This behavior is in line with previous works (Grasso, 1976; Grasso and Johnson, 1977; Gurcay et al., 1971) that have indicated at possible growth inhibition when exposed to GCs and later, a near-full recovery. Low cell viability was visible after 24 hours and reached its maximum after 48 hours with viability as low as $10 \%$ seen in the case of prednisolone $(5,15 \mu \mathrm{g} / \mathrm{ml})$ and NPs $(5$, $10 \mu \mathrm{g} / \mathrm{ml}$ ) when compared to control. Serum deprivation is known to cause cell death mainly due to necrosis rather than apoptosis and is enhanced by the presence of the GC and the activation of the GC receptors (Morita et al., 1999). C6 glial cells are also known to release specific neurotrophic growth factors that promote cell survival even in serum-deprived medium (Westermann et al., 1988) and along with this, GCs have also shown to influence protein synthesis in C6 cells (Lowe et al., 1992; Okumura et al., 1989; Pishak and Phillips, 1980).

\section{Detection of pro-inflammatory cytokines}

LPS was used to stimulate pro-inflammatory cytokine production in the $\mathrm{C} 6$ cells. The supernatants from the different treatments were employed for evaluating the TNF- $\alpha$ (Fig. 8A) and NO levels (Fig. 8B). Both prednisolone and the NPs showed considerable attenuation of TNF- $\alpha$ for the 24 and 48 hours groups. The samples treated with the free drug showed significantly $(p<0.05)$ higher amount of TNF- $\alpha$ release for 72 hours of incubation, whereas the levels were considerably lower for all the NP treated groups.

In addition to LPS induced cytokine production, serum deprivation and GC induced necrosis may have further augmented the levels of TNF- $\alpha$. The short half-life of prednisolone (Bindreither et al., 2014) could have also resulted in lesser attenuation of TNF- $\alpha$ for 72 hours of incubated groups treated with prednisolone alone. Control groups showed some amount of TNF- $\alpha$ release on all three days which may be again attributed to a combination effect of LPS and serum deprivation. Lower cell death due to the absence of drug in control may have helped keep the cytokine levels low. Sustained release of drug from the NPs could have helped maintain a therapeutic concentration (Shah et al., 2009) resulting in better anti-inflammatory effect as compared to the free drug (Pinto et al., 2019; Wang et al., 2009).

LPS induced NO production in C6 cells is known to be very low due to several factors that impede NF- $\mathrm{BB}$ activation and Inducible nitric oxide synthase (iNOS) expression (Feinstein

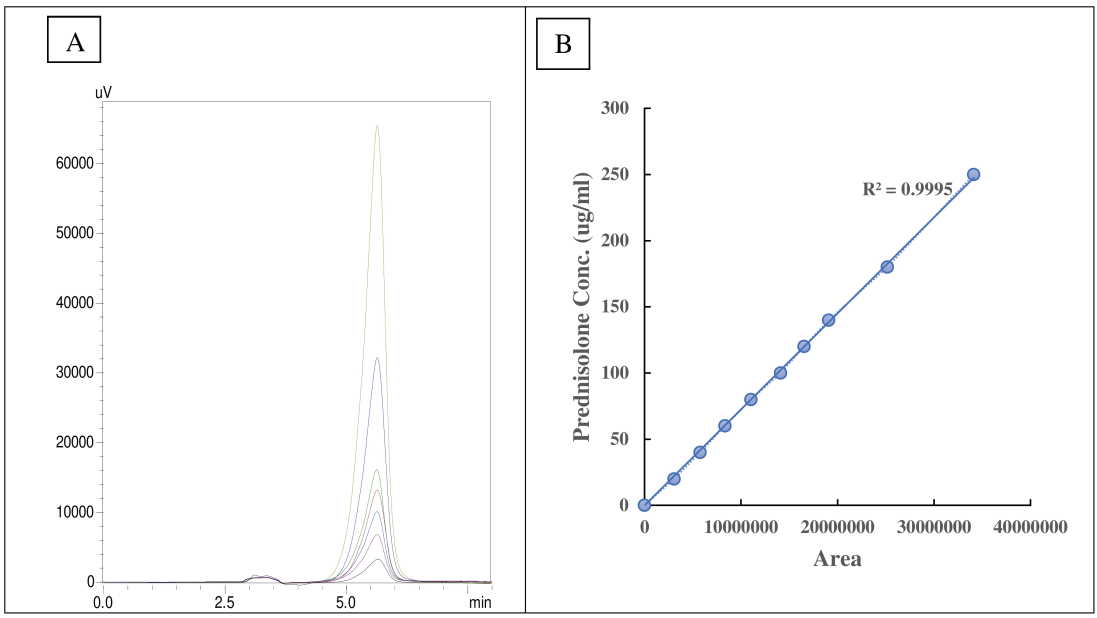

Figure 3. Standard calibration plots for prednisolone (A) chromatogram peaks $\left(R_{\mathrm{t}}=5.8\right.$ minutes) and (B) standard concentration curve.

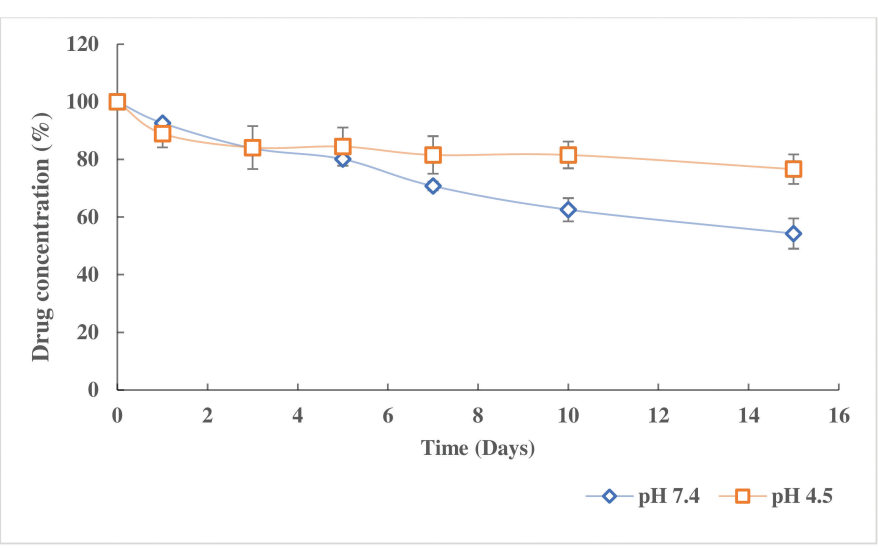

Figure 4. Stability plot for prednisolone drug at $\mathrm{pH} 7.4$ and $\mathrm{pH} 4.5$.

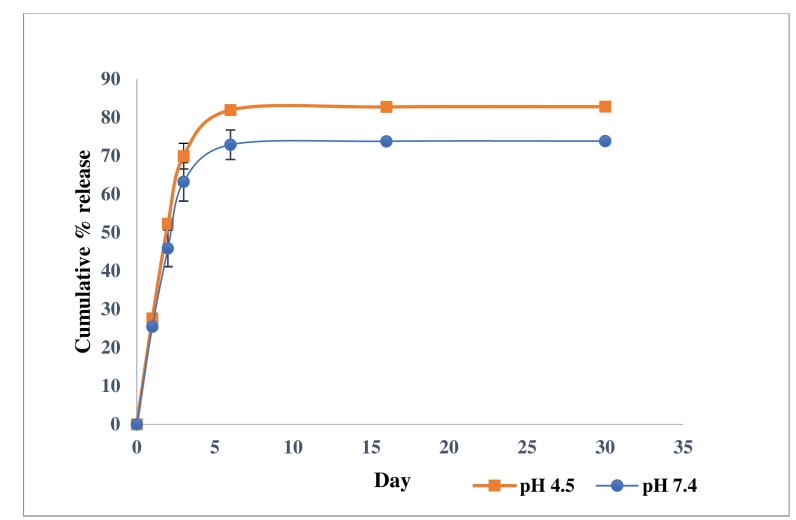

Figure 5. Drug release from prednisolone loaded PLGA NPs at $\mathrm{pH} 7.4$ and pH 4.5 . 


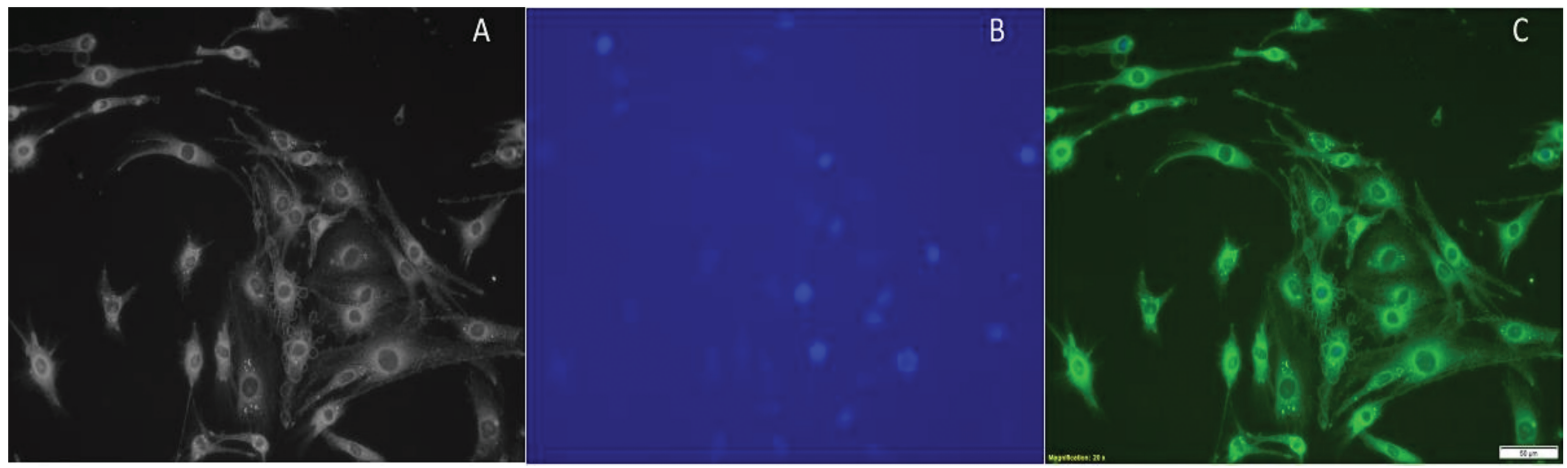

Figure 6. Localization of coumarin-6 loaded NPs in C6 glial cells (A) bright field, (B) DAPI, and (C) merged.

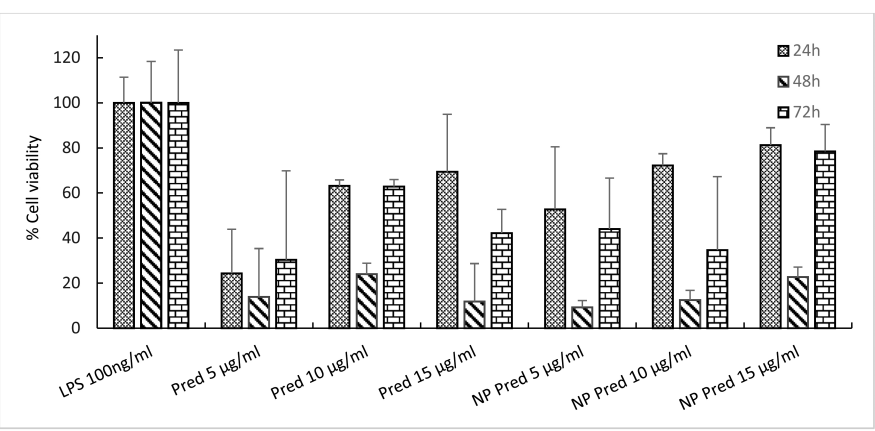

Figure 7. Effect of prednisolone and NPs on cell viability in C6 glial cells. Cells were incubated in serum-free medium and LPS (100 ng/ml). Specific groups were treated with the free drug (Pred. 5, 10, $15 \mu \mathrm{g} / \mathrm{ml}$ ) and NPs (NP Pred. 5, 10, $15 \mu \mathrm{g} / \mathrm{ml})$ for different time periods $(24,48$, and 72 hours), and the cell viability was determined. Values are expressed as mean $\pm \mathrm{SD}(n=3)$.

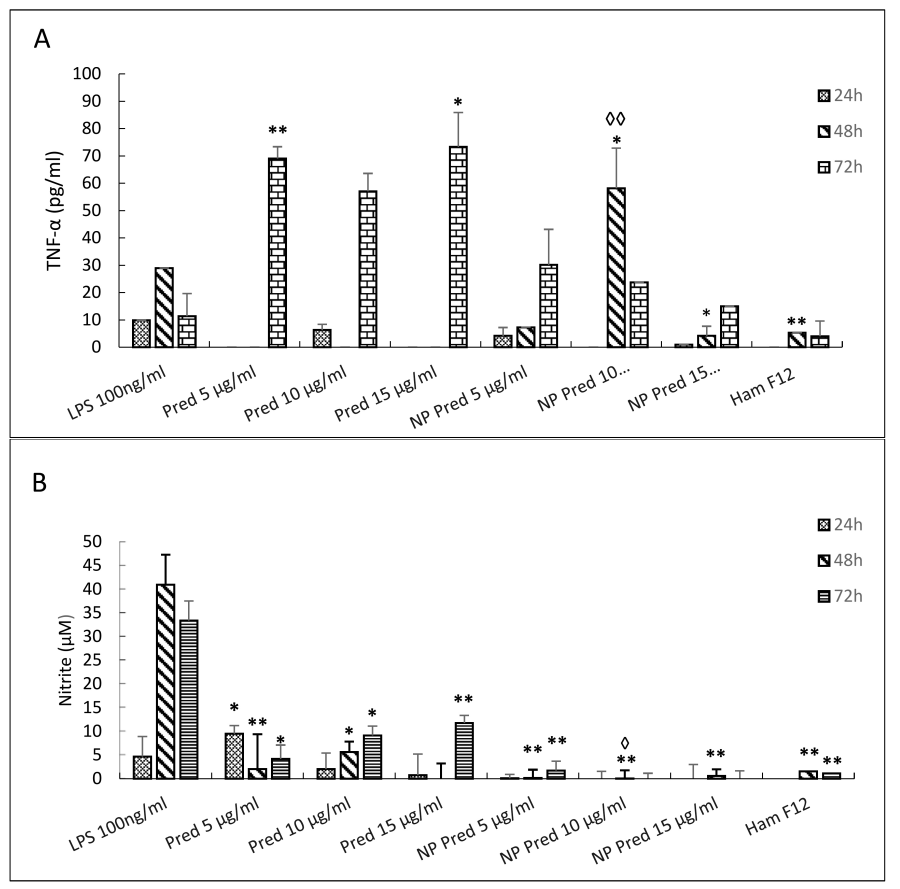

Figure 8. Effect of prednisolone and NPs on LPS induced (A) TNF- $\alpha$ and (B) nitrite production in C6 glial cell. Values are mean $\pm \mathrm{SD}, n=3 ; *(p<0.05)$, $* *(p<0.01)$ versus group of LPS; $\diamond(p<0.05), \diamond \diamond(p<0.01)$ versus group of prednisolone in the same concentration. et al., 1994; Mazzio et al., 2002; Pahan et al., 1999). Control group showed low levels of nitrite at 24 hours of incubation but later an increase in the levels was witnessed, which could be attributed to a combined effect of LPS, serum deprivation, and longer incubation time (Shin et al., 2002; Shinoda et al., 2003; Zhang et al., 1999). Prednisolone treatment significantly $(p<0.01)$ reduced the NO levels for all groups (Shin et al., 2002) during the 24 and 48 hours of incubation but a marked increase in levels was seen for 72 hours of incubated samples treated with the free drug. On the other hand, NP treated cells showed significantly $(p<0.05)$ lower levels of nitrite for all days thus maintaining a better inhibitory effect on the pro-inflammatory signals.

\section{CONCLUSION}

In an attempt to study the effects of prednisolone loaded PLGA nanoformulations on C6 cells, we synthesized and characterized NPs for size, zeta, and drug loading. The in vitro drug release exhibited a biphasic release profile. Optimum formulations were employed to evaluate the cytotoxic and antiinflammatory effects on C6 glial cells when compared to the free drug. The PLGA NPs provided protection to the drug and assisted in a slower release. The drug encapsulated in the NPs was able to significantly control the release of cytokines for longer periods when compared to the free drug. Both the free drug and NPs encapsulated with the drug appear to cause high growth inhibition, but at the same time, attenuation of pro-inflammatory cytokines was improved by the presence of the polymer carrier.

\section{ACKNOWLEDGMENT}

We thank the Department of Biotechnology, Chemical Engineering and the other associated institutes of Manipal Academy of Higher Education for providing the facilities to carry out our work.

\section{CONFLICT OF INTEREST}

The authors declare that there are no conflicts of interest.

\section{REFERENCES}

Baschant U, Tuckermann J. The role of the glucocorticoid receptor in inflammation and immunity. J Steroid Biochem Mol Biol 2010; 120:69-75.

Bindreither D, Ecker S, Gschirr B, Kofler A, Kofler R, Rainer J. The synthetic glucocorticoids prednisolone and dexamethasone regulate the same genes in acute lymphoblastic leukemia cells. BMC Genomics 2014; 15:662. 
Boekhorst te BCM, Jensen LB, Colombo S, Varkouhi AK, Schiffelers RM, Lammers T, Storm G, Nielsen HM, Strijkers GJ, Foged C, Nicolay K. MRI-assessed therapeutic effects of locally administered PLGA nanoparticles loaded with anti-inflammatory siRNA in a murine arthritis model. J Controlled Release 2012; 161:772-80.

Brown ES, Chandler AP. Mood and cognitive changes during systemic corticosteroid therapy. Prim Care Companion J Clin Psychiatry $2001 ; 3: 17-21$.

Christoper GVP, Raghavan CV, Siddharth K, Kumar MSS, Prasad RH. Formulation and optimization of coated PLGA - Zidovudine nanoparticles using factorial design and in vitro in vivo evaluations to determine brain targeting efficiency. Saudi Pharm J 2014; 22:133-40.

Ciriaco M, Ventrice P, Russo G, Scicchitano M, Mazzitello G, Scicchitano F, Russo E. Corticosteroid-related central nervous system side effects. J Pharmacol Pharmacother 2013; 4:S94-8.

Clark AR, Belvisi MG. Maps and legends: the quest for dissociated ligands of the glucocorticoid receptor. Pharmacol Ther 2012; 134:54-67.

Cooper DL, Harirforoosh S. Design and optimization of PLGA-based diclofenac loaded nanoparticles. PLoS One 2014; 9:e87326.

Danhier F, Ansorena E, Silva JM, Coco R, Le Breton A, Preat V. PLGA-based nanoparticles: an overview of biomedical applications. J Control Release 2012; 161:505-22.

ElShaer A, Mustafa S, Kasar M, Thapa S, Ghatora B, Alany RG. Nanoparticle-laden contact lens for controlled ocular delivery of prednisolone: formulation optimization using statistical experimental design. Pharmaceutics 2016; 8(2).

Feinstein DL, Galea E, Roberts S, Berquist H, Wang H, Reis DJ. Induction of nitric oxide synthase in rat C6 glioma cells. J Neurochem 1994; 62:315-21.

Feng S, Huang G. Effects of emulsifiers on the controlled release of paclitaxel (Taxol) from nanospheres of biodegradable polymers. J Control Release 2001; 1:53-69.

Ford Versypt AN, Pack DW, Braatz RD. Mathematical modeling of drug delivery from autocatalytically degradable PLGA microspheres-a review. J Control Res 2013; 165:29-37.

Giovagnoli S, Blasi P, Ricci M, Schoubben A, Perioli L, Ross C. Physicochemical characterization and release mechanism of a novel prednisone biodegradable microsphere formulation. J Pharm Sci 2008; 97:303-17.

Grasso RJ, Johnson CE. Dose-response relationships between glucocorticoids and growth inhibition in rat glioma monolayer cultures (39645). Proc Soc Exp Biol Med 1977; 154:238-241.

Grasso RJ. Transient inhibition of cell proliferation by glucocorticoids in rat glioma monolayer cultures. Cancer Res 1976; $36: 2408-14$.

Gurcay O, Wilson C, Barker M, Eliason, J. Corticosteroid effect on transplantable cat glioma. Arch Neurol 1971; 24:266-9.

Inaba $\mathrm{H}$, Pui $\mathrm{CH}$. Glucocorticoid use in acute lymphoblastic leukaemia. Lancet Oncol 2010; 11:1096-106.

Jiang J, Oberdorster G, Biswas P. Characterization of size, surface charge, and agglomeration state of nanoparticle dispersions for toxicological studies. J Nanopart Res 2009; 11:77-89.

Khaled KA, Sarhan HA, Ibrahim MA, Ali AH, Naguib YW. Prednisolone-loaded PLGA microspheres. In vitro characterization and in vivo application in adjuvant-induced arthritis in mice. AAPS Pharm Sci Tech 2010; 11(2):859-69.

Lin KT, Wang LH. New dimension of glucocorticoids in cancer treatment. Steroids 2016; 111:84-8.

Locatelli E, Franchini MC. Biodegradable PLGA-b-PEG polymeric nanoparticles: synthesis, properties, and nanomedical applications as drug delivery system. J Nanopart Res 2012; 14:1316.

Lowe WL Jr, Meyer T, Karpen CW, Lorentzen LR. Regulation of insulin-like growth factor I production in rat C6 glioma cells: possible role as an autocrine/paracrine growth factor. Endocrinology 1992; 130:2683-91.
Makadia HK, Siegel SJ. Poly lactic-co-glycolic acid (PLGA) as biodegradable controlled drug delivery carrier. Polymers (Basel) 2011; 3:1377-97.

Mazzio E, Becker A, Soliman KF. Characterization of neurotransmitters and dopamine attenuation of inducible nitric oxide synthase in glioma cells. J Neuroimmunol 2002; 131:70-82.

Morita K, Ishimura K, Tsuruo Y, Wong DL. Dexamethasone enhances serum deprivation-induced necrotic death of rat C6 glioma cells through activation of glucocorticoid receptors. Brain Res 1999; 816(2):30916.

Mundargi RC, Babu VR, Rangaswamy V, Patel P, Aminabhavi TM. Nano/micro technologies for delivering macromolecular therapeutics using poly (D, L lactide co-glycolide) and its derivatives. J Control Release 2008; 125:193-209.

Nicolete R, Santos D, Faccioli L. The uptake of PLGA micro or nanoparticles by macrophages provokes distinct in vitro inflammatory response. Int Immunopharmacol 2011; 11:1557-63.

Okumura N, Takimoto K, Okada M, Nakagawa H. C6 glioma cells produce basic fibroblast growth factor that can stimulate their own proliferation. J Biochem 1989; 106:904-9.

Pahan K, Raymond JR, Singh I. Inhibition of phosphatidylinositol 3-kinase induces nitric-oxide synthase in lipopolysaccharide- or cytokinestimulated C6 glial cells. J Biol Chem 1999; 274:7528-36.

Panyam J, William D, Dash A, Leslie-Pelecky D, Labhasetwar V. Solid-state solubility influences encapsulation and release of hydrophobic drugs from PLGA/PLA nanoparticles. J Pharm Sci 2004; 93:1804-14.

Pinto J, Ahmad M, Guru B R. Enhancing the efficacy of fluocinolone acetonide by encapsulating with PLGA nanoparticles and conjugating with linear PEG polymer. J Biomater Sci Polym Ed 2019; 30:1188-211.

Pishak MR, Phillips AT. Glucocorticoid stimulation of glutamic synthetase production in cultured rat glioma cells. J Neurochem 1980; 34:866-872.

Shah N, Chaudhari K, Dantuluri P, Murthy RS, Das S Paclitaxel-loaded PLGA nanoparticles surface modified with transferrin and Pluronic ${ }^{\circledR P} 85$, an in vitro cell line and in vivo biodistribution studies on rat model. J Drug Target 2009; 17:533-42.

Shin JH, Kang KS, Kim JY, Kim SZ, Park JY, Kwak EK, Sohn YK. Lipopolysaccharide/interferon-gamma induced nitric oxide production in C6 glioma cells: modulation by dexamethasone. J Pathol Transl Med 2002; 36:406-11.

Shinoda J, McLaughlin KE, Bell HS, Swaroop GR, Yamaguchi S, Holmes MC, Whittle IR. Molecular mechanisms underlying dexamethasone inhibition of iNOS expression and activity in C6 glioma cells. Glia 2003; 42:68-76

Shive MS, Anderson JM. Biodegradation and biocompatibility of PLA and PLGA microspheres. Adv Drug Deliv Rev 1997; 28:5-24.

Song X, Zhao Y, Hou S, Xu F, Zhao R, He J, Cai Z, Li Y, Chen Q. Dual agents loaded PLGA nano-particles: systematic study of particle size and drug entrapment efficiency. Eur J Pharm Biopharm 2009; 69 $445-53$

Srivastava P, Mohanti S, Bawankule DU, Khan F, Shanker K. Effect of pluchea lanceolata bioactives in LPS-induced neuroinflammation in C6 rat glial cells. Naunyn Schmiedebergs Arch Pharmacol 2013; 387:119-27.

Todd FD, Miller CA, Yates AJ, Mervis LJ. Steroid-induced remission in primary malignant lymphoma of the central nervous system. Surg Neurol 1986; 26:79-84.

Wang B, Navath RS, Romero R, Kannan S, Kannan R. Antiinflammatory and anti-oxidant activity of anionic dendrimer-N-acety cysteine conjugates in activated microglial cells. Int J Pharm 2009; 377:159-68.

Westermann R, Hardung M, Meyer DK, Ehrhard P, Otten U, Unsicker K. Neuronotrophic factors released by C6 glioma cells. J Neurochem 1988; 50:1747-58. 
Zhang WY, Takiguchi M, Koshiyama Y, Gotoh T, Nagasaki A, Iwase K, Yamamoto K, Takeshima H, Negi A, Mori M. Expression of citrulline-nitric oxide cycle in lipopolysaccharide and cytokine-stimulated rat astroglioma C6 cells. Brain Res, 1999; 849:78-84.
How to cite this article:

Acharya S, Guru BR. Prednisolone encapsulated PLGA nanoparticles: Characterization, cytotoxicity, and antiinflammatory activity on C6 glial cells. J Appl Pharm Sci, 2020; 10(04):014-021. 